\title{
Separate housing for one month after calving improves production and health in primiparous cows but not in multiparous cows
}

\author{
S. Østergaard, ${ }^{1}$ P. T. Thomsen, and E. Burow \\ Department of Animal Health and Bioscience, Faculty of Agricultural Sciences, University of Aarhus, Research Centre Foulum, PO Box 50, \\ DK-8830 Tjele, Denmark
}

\begin{abstract}
The hypothesis was that dairy cows housed for 1 mo after calving in a separate group with herd mates would produce more milk and would be healthier than cows integrated in a group of all lactating cows immediately after calving. The experiment was conducted with 489 cows in 6 commercial loose-housing dairy herds where cows were randomly selected for treatment (separate housing) or control. Cows selected for treatment were housed for 1 mo after calving in a separate section, and controls were housed in the remaining section of the barn for lactating cows. Data were compared for milk yield, somatic cell count, medical treatments, reproductive performance, culling, mortality, and clinical observation of scores for body condition, leg and udder hygiene, lameness, hock lesions, other cutaneous lesions, vaginal discharge, and condition of the hair coat. The analysis of the effect of separate housing showed that primiparous cows produced more milk [approximately $230 \mathrm{~kg}$ of energy-corrected milk from 0 to $305 \mathrm{~d}$ in milk (DIM)], whereas multiparous and especially parity $3+$ cows produced less milk (approximately $394 \mathrm{~kg}$ of energy-corrected milk from 0 to 305 DIM) during the lactation. Separate housing had no effect on mortality or reproductive efficiency. In primiparous cows, the number of medical treatments for ketosis was reduced by separate housing [hazard ratio $0.33,95 \%$ confidence interval (CI): 0.13-0.83]. Clinical evaluations showed that separate housing decreased the scores for hock lesions in cows at 0 to 30 DIM (odds ratio 0.41, CI: 0.19-0.91), whereas the scoring of leg cleanliness showed more dirty legs in separated cows at 0 to 30 DIM (odds ratio 3.61, CI: 2.01-6.47) compared with cows integrated into the herd immediately. The body condition score in separated cows was reduced from 0 to 30 DIM (score reduced by 0.16 , CI: $0.07-0.25$ ) and from 31 to 60 DIM (score reduced by 0.13, CI: 0.04-0.23) compared with cows integrated immediately. We concluded that
\end{abstract}

Received October 29, 2009.

Accepted April 9, 2010.

${ }^{1}$ Corresponding author: soren.ostergaard@agrsci.dk separate housing for 1 mo after calving increased milk yield in primiparous cows but not in multiparous cows, which produced less milk. The hypothesis about fewer health problems could only be confirmed with regard to fewer primiparous cows being treated for ketosis.

Key words: separate housing, dairy cow, grouping, milk yield

\section{INTRODUCTION}

To improve production efficiency in modern dairy production systems, the number of cows per herd has increased, cows are housed in larger groups, and the number of hours of labor per cow has decreased (Caraviello et al., 2006). In this situation, cows with low social status can have difficulties gaining access to resources (Kjæstad, 1999; Bach et al., 2006; Rioja-Lang et al., 2009) and may become stressed. The manual monitoring of cows may be insufficient because of the large group size and low number of hours of labor per cow. These circumstances may reduce animal welfare and production performance. Accordingly, Albeni and Betoni (2009) and Bøe and Færevik (2003) support the separation of primiparous cows after calving from multiparous cows. Experiments on the housing of primiparous cows separate from older cows have shown positive effects on their behavior, DMI, and milk yield (Krohn and Kongaard, 1979; O'Connell et al., 2008). However, O'Connell et al. (2008) reported these effects for primiparous cows that were separated for $1 \mathrm{wk}$ and only if introduced to the herd as pairs and not individually. A longer separation period might improve the welfare and production of individually introduced cows. To efficiently combine the managerial benefits of housing of large groups of cows with the welfare and production benefits of grouping of cows in smaller groups, it is necessary to test alternative grouping strategies. When evaluating grouping strategies it is relevant to focus on the cows that suffer the most in large groups. Cows in the postcalving period must have the capacity for high milk yield and they account for the greatest number of medical treatments for health problems. Grouping these cows separately under good housing conditions 
may allow manual monitoring to be more focused on those cows with the highest risk of health problems. In this way, health problems may be identified earlier and detrimental effects may be reduced.

Thus, the hypothesis was that dairy cows housed for 1 mo after calving in a separate group with herd mates in the same lactation period would produce more milk and be healthier than cows integrated into the group of all remaining lactating cows just after calving.

To test this, an experiment was conducted with 489 cows in 6 commercial loose-housing dairy herds where cows were randomly selected for treatment (separate housing) and control. Cows selected for treatment were housed for $1 \mathrm{mo}$ after calving in a separate section of the barn to allow more attention for these cows. Cows selected as controls were housed in the remaining section of the barn that housed all other nontreatment cows as well as those treatment cows that had left the separate section after 1 mo. All cows were followed for at least 8 mo, and most cows were followed until the end of the lactation. Data for milk yield, SCC, medical treatments, reproductive performance, culling, mortality, and clinical observations of scores for body condition, leg and udder hygiene, lameness, hock lesions, other cutaneous lesions, vaginal discharge, and condition of the hair coat were compared.

\section{MATERIALS AND METHODS}

\section{Herds and Experimental Design}

Six Danish dairy herds located in the west of Denmark (Jutland) were selected for the study using the following inclusion criteria: free-stall loose-housing system, milking in parlors twice daily, routine milk recording, and a herd size of $>130$ cows. In addition, farmers should be able to establish special pen sections for $10 \%$ of their cows within the main free-stall barn.

The herds shared characteristics with similar, large Danish dairy herds (Danish Agriculture and Food Council, 2009) and included 1 organic herd and 5 conventional herds. Herd size ranged from 135 to 250 cows with an average of 177 cows. Milk production ranged from 8,500 to $10,900 \mathrm{~kg}$ with an average of $9,900 \mathrm{~kg}$ of ECM/yr per cow. The SCC ranged from 223,000 to 340,000 with an average of 285,000 cells/mL. In 2008, $10 \%$ of the Danish dairy herds were organic herds. In 2008, the averages for all conventional Danish dairy herds exclusive of herds with Jersey cows were 126 cows, 9,200 kg of ECM, and an SCC of 299,000.

In the herds, a separate section with room for approximately $10 \%$ of the cows was established for the cows selected for treatment. This treatment section was integrated into the rest of the free-stall barn of milk- ing cows but separated by fences. The treatment and control sections had the same free-stall loose-housing system with identical equipment and access to the same feed bunk and feed. Farmers were not allowed to feed cows in the separate treatment section with special or additional feed. The separate treatment section offered at least 1 free-stall and 1 feeding place per cow as well as $5 \%$ additional space compared with the control section of the barn. The separate treatment section was established within each farm for 4 to 9 mo consecutively during the period from February 2007 to August 2008.

To randomize the cows, farmers were instructed to allocate cows with even-numbered ear tags to the treatment section and cows with odd-numbered ear tags to the control group. In total, 489 cows were included. The treatment cows entered the separate treatment section the day after calving and left the separate treatment section at 30 DIM. After the 1-mo treatment period, the separately housed cows were regrouped to the control section. A cow selected for control was included in the analysis if it did not enter the separate treatment section during its entire lactation.

Consistency in allocation of cows to treatment and control groups was confirmed during the visits for clinical examination. Some deviations were introduced by the farmers, which meant that some cows were moved some days too early or some days too late. Accordingly, 21 cows that stayed for $<15 \mathrm{~d}$ in the separate treatment section were excluded. Of the remaining 217 cows selected for treatment, $75.6 \%$ entered the separate treatment section directly on the day after calving, $4.6 \%$ up to $7 \mathrm{~d}$ before, and $19.8 \%$ up to $9 \mathrm{~d}$ after calving.

The distribution of cows across herds and treatment versus control are in Table 1 . The mean lactation number for both treatment and control cows was 2.2. Thirty-eight percent of all cows were primiparous (range: 32 to $43 \%$ ). Thirty-eight percent of the treatment cows were primiparous (range: 28 to $63 \%$ ). The distribution of cows in the 2 groups with respect to breed was 314 Danish Holstein, 43 Jersey, 111 Danish Red, and 21 other breeds.

\section{Data}

A clinical evaluation including BCS, lameness, hock lesions, other cutaneous lesions, vaginal discharge and condition of the hair coat was made using the scoring systems described by Ferguson et al. (1994; BCS) and Thomsen et al. (2007; all other scores). Additionally, leg and udder hygiene was recorded (Schreiner and Ruegg, 2003).

The clinical examination was done 3 times during the study period. The first examination was at the beginning, the second in the middle, and the third at the 
Table 1. Number of cows in the experiment and their distribution among herds and parities

\begin{tabular}{|c|c|c|c|c|c|}
\hline \multirow{3}{*}{$\begin{array}{l}\text { Herd } \\
\text { number }\end{array}$} & \multirow{3}{*}{$\begin{array}{c}\text { Herd } \\
\text { size }(n)\end{array}$} & \multicolumn{4}{|c|}{ Number of cows in experiment ${ }^{1}$} \\
\hline & & \multicolumn{2}{|c|}{ All parities } & \multicolumn{2}{|c|}{ Primiparous cows } \\
\hline & & Treatment & Control & Treatment & Control \\
\hline 1 & 195 & 61 & 87 & 22 & 34 \\
\hline 2 & 145 & 29 & 39 & 9 & 16 \\
\hline 3 & 185 & 27 & 30 & 17 & 7 \\
\hline 4 & 135 & 31 & 28 & 11 & 9 \\
\hline 5 & 250 & 44 & 69 & 17 & 32 \\
\hline 6 & 150 & 25 & 19 & 7 & 7 \\
\hline All herds & & 217 & 272 & 83 & 105 \\
\hline
\end{tabular}

${ }^{1}$ Cows selected for treatment were housed for 1 mo after calving in a separate section, and controls were housed in the remaining section of the barn for lactating cows.

end of the study period. During the first visit, all cows that had already entered the experiment or that would calve within the following 10 wk were examined. During the second visit, all cows that had already entered the experiment or that would calve within the next 10 wk were examined. During the third visit, all cows that had already entered the experiment were examined. Some of the cows could not be examined for practical reasons (e.g., observer unable to find the cow); others were culled before the second or third examination. Clinical scoring was done 3 times in 141 cows, twice in 163 cows, and once in 75 cows. In total, 379 cows were clinically scored. The mean number of days from calving to day of clinical scoring was $-27,43$, and $110 \mathrm{~d}$ for the first, second, and third scorings, respectively. All cows were examined by the same experienced veterinarian, who had developed the scoring system and used it on more than 15,000 cows previously. Intra- and interobserver agreement was evaluated using prevalenceadjusted bias-adjusted Kappa (PABAK); PABAK for intra-observer agreement ranged from 0.80 to 0.98 and PABAK for inter-observer agreement ranged from 0.56 to 0.84) (Thomsen and Baadsgaard, 2006).

The clinical scorings were transformed into a dichotomous system with score 1 representing the normal (healthy) condition and score $\geq 2$ representing increasing degrees of deviation from this normal condition. Details about the clinical scoring system can be found in Thomsen et al. (2007). The threshold between healthy and diseased was relatively low to detect diseased cows that showed only mild clinical signs (Thomsen and Baadsgaard, 2006). The implication was that there might be a relatively high number of false positive assessments. Nevertheless, for this study, it was important to find all diseased cows and therefore a higher number of false positives was accepted to avoid too many false negatives.
With very few exceptions, only veterinarians were allowed to treat cows with antibiotics or other medications in Danish dairy herds (according to Danish law). All diseases treated by a veterinarian and movements of cattle (death, slaughter, or sale for dairy purposes) were recorded in the Danish Cattle Database. Individual cow test-day milk yield was recorded approximately monthly for cows in 5 of the 6 farms and recorded every second month for 1 herd. Reproduction was analyzed based on information on $\mathrm{AI}$ and calving data from the Danish Cattle Database.

When the data were retrieved from the database, 38 of the treatment cows and 49 of the control cows had not yet finished the lactation. Most of these cows came from 1 herd and all of these had exceeded 200 DIM.

\section{Statistical Models}

For the statistical analyses of continuous and binary response variables with repeated measures within the individual cow, random regression models with repeated measures for the continuous and binary outcome measures were used. For data of reproduction, culling, and medical treatment event, survival analyses were used supplemented by chi-squared test.

Test-day yield of ECM $(\mathrm{kg})$ was calculated as $[\mathrm{kg}$ of milk $\times(383 \times$ fat $\%+242 \times$ protein $\%+780.8)] / 3,140$. To analyze the effect of separate housing on test-day yield of ECM, PROC MIXED (SAS Institute, 2009) was used with a random regression model in which the individual cow was the experimental unit and where measurements were carried out on the same cow during the lactation. Each cow contributed 1 lactation only. Time-sequence analysis was modeled by using the random part of the models with 3 lactation curve parameters that differed randomly among the cows. Correlation between the parameters was modeled with an 
unstructured covariance matrix. The 3 lactation curve parameters were intercept, linear slope to peak yield at 60 DIM, and linear slope after peak yield at 60 DIM. The lactation curves were fitted similarly to those described by Bennedsgaard et al. (2003). The fixed covariates in the model included lactation curve parameters (those in the random part of the model and supplemented by correction for late pregnancy according to Strandberg and Lundberg, 1991), farm (1, 2 .. 6), calving quarter, breed (Danish Holstein, Jersey, Danish Red, and other breeds), parity $(1,2,3+)$, breeding index for milk yield (continuous), and index for experimental treatment group. The index for the experimental treatment group was as follows: 1 for treatment cows 0 to 30 DIM, 2 for treatment cows 31 to 60 DIM, 3 for treatment cows 61 to 90 DIM, 4 for treatment cows 91 to 150 DIM, 5 for treatment cows $>150$ DIM, and 6 for control cows. Data for test-day yield of ECM were not included after 365 DIM. The modeling strategy included test for significance of main effects and 2 factor interactions. Alternative grouping of parity into only primiparous and multiparous cows was tested, and separate models for each parity were estimated.

For the effects of separate housing on test-day SCC, both the natural logarithm of the SCC (LNSCC) and a binary outcome according to SCC being above or not above 200,000 cells/mL (SCC200) were analyzed. The natural $\log$ SCC was analyzed using the same modeling principle as used for test-day yield of ECM, but the lactation curves were modeled by a third-order polynomial of DIM in the fixed part of the model and by an intercept and a linear slope in the random part of the model. To analyze the effect of separate housing on SCC200, PROC GENMOD (SAS Institute, 2009) was used with a generalized linear model with binary outcome and a logit link function where the individual cow was the experimental unit and where measurements were carried out on the same cow during the lactation. The time-sequence was modeled by the GEE1 model specification, where measurements within the same cow were specified to be chronologically ordered (Molenberghs and Verbeke, 2005). The lactation curves were modeled by a third-order polynomial of DIM in the fixed part of the model. The other fixed effects were specified as in the model for test-day yield of ECM except for the milk yield breeding index parameter.

To analyze the effect of separate housing on clinical scores, dichotomized scores were used and each clinical score was analyzed separately with a model like that used for SCC200. The untransformed clinical scores for BCS and lameness were analyzed by the same model used for LNSCC. However, for the clinical scores, the index for the experimental treatment group was modified by merging experimental treatment group 90 to 150
DIM and >150 DIM. All clinical scores before calving were included in the index for control cows.

To analyze the effect of separate housing on time from calving to events regarding culling, medical treatments, and reproduction, PROC PHREG was used in SAS (SAS Institute, 2009) for a Cox semiparametric model for survival data to study the effect on hazard ratios. This proportional hazards model seemed appropriate, because the estimates of the $\log [-\log ($ SURVIVAL) $]$ plotted against the $\log$ (DIM) variable gave approximately parallel lines. Survival times were censored at the first event of 1) time of next calving, and 2) date of ending the data recording (March 31, 2009) if the cow did not experience the event under study. Treatment, parity, and treatment by parity interaction were included as fixed covariates and the modeling was stratified on herd. Cows culled due to slaughter and death (including euthanasia) were analyzed together as well as in separate models. For reproduction, survival analysis was used for the number of days from calving to first AI and calving interval. This was supplemented with a chi-squared test for separate housing having an effect on the chance of conception at first AI in cows where there were data for the next calving or at least 290 d after first AI. Survival analyses were used for medical treatment; only the first case of each medical treatment was considered in the analyses.

\section{RESULTS}

\section{Descriptive Statistics}

Descriptive statistics on the clinical scores and continuous response variables included in the analyses are summarized in Tables 2 and 3. For the binary response variables, the lactational incidence rates of the first case of medical treatments in the treatment and control groups were 0.037 and 0.026 for acyclic cows, 0.106 and 0.074 for early metritis, 0.005 and 0.004 for cysts, 0.097 and 0.051 for retained placenta, 0.226 and 0.265 for mastitis, 0.014 and 0.007 for teat injuries, 0.152 and 0.217 for ketosis, 0.023 and 0.018 for milk fever, 0.018 and 0.007 for displaced abomasum, 0.032 and 0.033 for other digestive disorders, 0.046 and 0.085 for infectious hoof disorders, 0.005 and zero for other hoof disorders, 0.037 and 0.029 for leg disorders, and zero and 0.011 for abortions. Among the 151 and 181 cows in the treatment and the control groups where there were data to the next calving or at least $290 \mathrm{~d}$ after the first AI, 54 and $56 \%$, respectively, conceived at the first AI.

\section{Milk Production}

The analyses of the effect of separate housing on milk yield using the model with all parities did not reveal an 
Table 2. Descriptive statistics on the clinical scores for cows in separate housing for 1 mo after calving and for control cows ${ }^{1}$

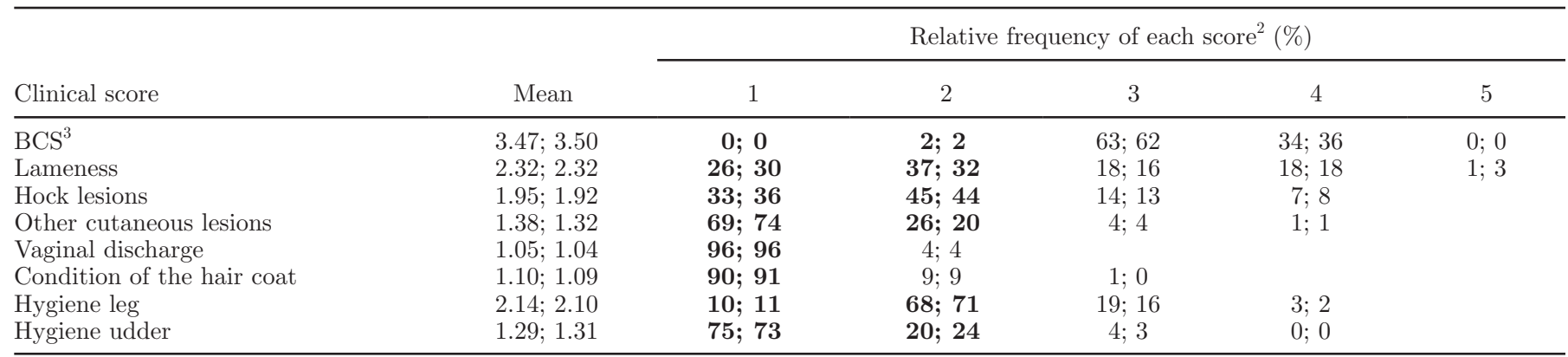

${ }^{1}$ Values separated by semicolon are for the treatment $(\mathrm{n}=387)$ and the control $(\mathrm{n}=435)$ groups, respectively.

${ }^{2}$ Score 1 represents the normal condition and increasing scores represent increasing deviation from the normal condition (Thomsen et al., 2007 for details). Bold (versus not bold) figures indicates the threshold for defining normal and nonnormal conditions used in the analyses with binary response.

${ }^{3} \mathrm{BCS}$ was scored in intervals of 0.25 . For the relative frequencies in this table, the scores were rounded to the nearest integer.

interaction between parity and treatment $(P=0.142)$. However, the analyses revealed one-factor effects of parity $(1,2$, and $3+; P<0.001)$ and separate housing $(P=0.0014)$. The estimated effects on test-day yield of ECM relative to DIM in each parity estimated with parity-specific models are in Table 4. Except for the period 0 to 30 DIM, the estimates of effects on milk yield were positive in primiparous cows. In parity $3+$ cows, all estimates were negative except from period 0 to 30 DIM. In parity 2 cows, the estimates were between the estimates from parity 1 and parity $3+$ cows. By summarizing the estimates from 0 to 305 DIM, the total estimated effects were $230,-194$, and $-394 \mathrm{~kg}$ of ECM in parities 1, 2, and $3+$. There was no significant interaction between herd and treatment.

\section{SCC}

The SCC analyzed by LNSCC in the model for all parities showed an interaction between herd and treat- ment index $(P<0.0001)$. In the parity-specific models, this interaction was apparent only in the model for parity $3+$ cows. The SCC analyzed by SCC200 in the model for parity 1 showed no effect of treatment $(P=$ $0.07)$. There was no significant effect of separate housing on SCC200 in the models for parities 2 and $3+$.

\section{Culling and Mortality}

Data for slaughter and death (including euthanasia) within the lactation of the experiment were analyzed together as well as in separate models. In Figure 1, the Kaplan-Meier estimate of the survival function is plotted for treatment and control cows, where failure included slaughtered and dead cows. The survival proportional hazards model for dead cows showed no significant difference in mortality between treatment and control groups. The survival proportional hazards model for slaughtered cows showed a hazard ratio of

Table 3. Descriptive statistics on the analyzed response variables measured on a continuous scale for cows in separate housing for 1 mo after calving and for control cows ${ }^{1}$

\begin{tabular}{|c|c|c|c|c|}
\hline \multirow[b]{2}{*}{ Response variable } & \multirow[b]{2}{*}{$\mathrm{n}$} & \multicolumn{3}{|c|}{ Percentile } \\
\hline & & $10 \%$ & $50 \%$ & $90 \%$ \\
\hline \multicolumn{5}{|l|}{ Test-day ECM ${ }^{2}$} \\
\hline Parity 1 & $776 ; 896$ & $20.8 ; 19.8$ & $27.0 ; 26.9$ & $33.2 ; 34.2$ \\
\hline Parity 2 & $544 ; 753$ & $18.4 ; 19.0$ & $30.6 ; 32.0$ & $40.4 ; 41.2$ \\
\hline Parity $3+$ & $551 ; 638$ & $18.9 ; 20.3$ & $32.1 ; 32.2$ & $43.6 ; 43.6$ \\
\hline LNSCC $^{3}$ & 1,$850 ; 2,262$ & $10.40 ; 10.40$ & $11.54 ; 11.54$ & $13.23 ; 13.24$ \\
\hline Mortality (DIM) & $13 ; 13$ & $33 ; 39$ & $58 ; 191$ & $233 ; 325$ \\
\hline Calving to first AI (d) & $193 ; 234$ & $36 ; 37$ & $72 ; 65$ & $136 ; 145$ \\
\hline Calving interval (d) & $136 ; 159$ & $334 ; 327$ & $379 ; 377$ & $477 ; 486$ \\
\hline
\end{tabular}




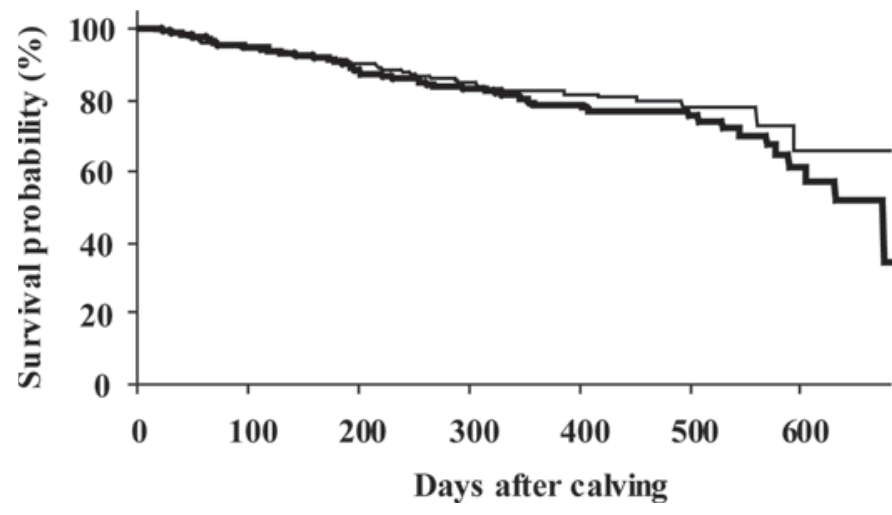

Figure 1. The Kaplan-Meier survival function for cows not dead or slaughtered plotted for cows separated from the entire herd for 1 mo (normal curve) and control (bold curve) cows.

$0.40(P=0.08)$ for treatment cows. There was no significant effect of parity or parity by treatment interaction. When slaughtered and dead cows were analyzed as one category, there was no effect of treatment $(P=$ $0.19)$.

\section{Reproduction Efficiency}

The median days from calving to the first AI were 72 and $65 \mathrm{~d}$ for treatment and control cows, respectively. The survival analyses on days to first AI showed no effect of treatment $(P=0.24)$. The median days from calving to the next calving were 379 and $377 \mathrm{~d}$ for treatment and control cows, respectively. The corresponding survival analyses showed no effect of separate housing $(P=0.77)$. The chi-squared test for the effect of treatment on the chance of conception at the first $\mathrm{AI}$ in cows, where there were data to the next calving or at least $290 \mathrm{~d}$ after the first AI, showed no effect of separate housing $(P=0.78)$. The chance of conception was not affected significantly when analyzed separately for each parity.

\section{Medical Treatments}

The survival analyses on days to the occurrence of disease showed no effect $(P>0.10)$ of medical treatment for all disorders except ketosis. The estimated effects of separate housing for 1 mo after calving on hazard ratio of occurrence of medical treatment for retained placenta, ketosis, and infectious hoof disorders and the lactational incidence rates are presented in Table 5. The survival analysis on medical treatments for ketosis revealed an interaction between parity and treatment $(P=0.035)$. The estimated hazard ratios of occurrence of medical treatments for ketosis showed that primiparous cows in the treatment group had an occurrence of medical treatments for ketosis approximately one-third that of cows in the control group. For retained placenta and infectious hoof disorders, there were no interactions with parity.

\section{Clinical Scores}

The model for the dichotomized clinical scores for hock lesions showed a significant effect of separate housing $(P=0.034)$. The risk was decreased from 0 to 30 DIM and increased from 30 to 60 DIM in treatment cows relative to control cows (Table 6). On the dichotomized scale $(0,1)$, the total mean score for hock lesions was 0.21 . The model for the dichotomized clinical scores for leg cleanliness (value 1 for dirty legs) showed a significant effect of separate housing $(P=$ 0.001). The risk of dirty legs from 0 to 30 DIM was increased in separately housed cows (Table 6). On the dichotomized scale $(0,1)$, the total mean score for leg hygiene was 0.19. There were no significant effects of treatment on the other dichotomized clinical scores. The model for the dichotomized clinical scores for BCS did not converge.

The BCS analyzed on the original scale with the random regression model showed an effect of treatment $(P=0.0003)$. The effects (and corresponding 95\% CI)

Table 4. Effects of separate housing for 1 mo on test-day yield of ECM (kg) estimated for 217 treatment cows versus 272 control cows

\begin{tabular}{|c|c|c|c|c|c|c|c|c|c|}
\hline \multirow[b]{3}{*}{ DIM } & \multicolumn{3}{|c|}{ Parity 1} & \multicolumn{3}{|c|}{ Parity 2} & \multicolumn{3}{|c|}{ Parity 3+ } \\
\hline & \multirow[b]{2}{*}{ Estimate } & \multicolumn{2}{|c|}{$95 \% \mathrm{CI}$} & \multirow[b]{2}{*}{ Estimate } & \multicolumn{2}{|c|}{$95 \% \mathrm{CI}$} & \multirow[b]{2}{*}{ Estimate } & \multicolumn{2}{|c|}{$95 \% \mathrm{CI}$} \\
\hline & & Lower & Upper & & Lower & Upper & & Lower & Upper \\
\hline 0 to 30 & -0.35 & -2.04 & 1.35 & -0.53 & -3.77 & 2.72 & 0.25 & -2.62 & 3.13 \\
\hline 31 to 60 & 0.49 & -1.00 & 1.97 & 0.79 & -1.47 & 3.06 & -0.93 & -3.32 & 1.46 \\
\hline 61 to 90 & 0.69 & -0.74 & 2.13 & -0.09 & -2.17 & 1.99 & -0.65 & -2.98 & 1.68 \\
\hline 91 to 150 & 0.34 & -0.98 & 1.67 & -1.10 & -3.00 & 0.81 & -2.08 & -4.16 & -0.02 \\
\hline$>150$ & 1.19 & -0.12 & 2.49 & -0.86 & -2.84 & 1.12 & -1.48 & -3.50 & 0.53 \\
\hline 0 to $305^{1}$ & 230 & & & -194 & & & -394 & & \\
\hline
\end{tabular}

${ }^{1}$ Sum of DIM periods weighted according to days in each period. 
Table 5. Effects of separate housing for 1 mo after calving on hazard ratio (HR) of occurrence of medical treatment for retained placenta, ketosis, and infectious hoof disorders estimated in separate Cox proportional hazard models and lactational incidence rates (LIR) in 217 treatment cows versus 272 control cows

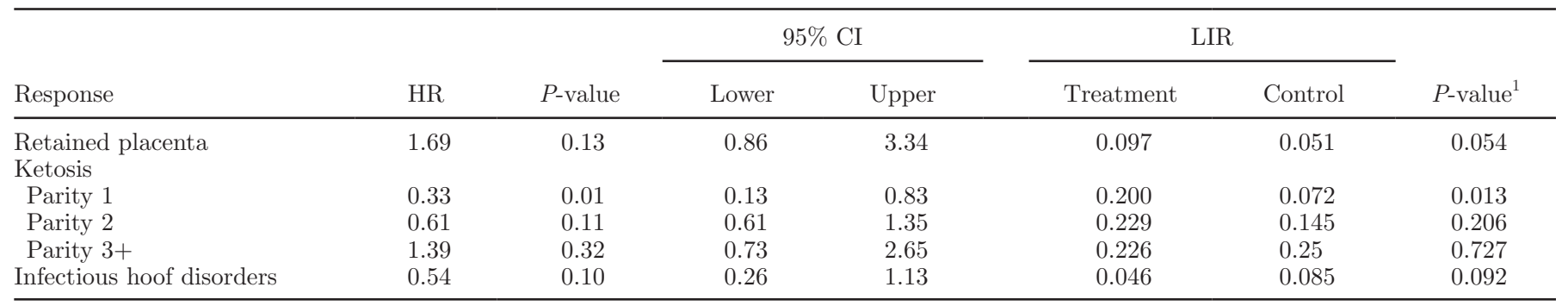

${ }^{1} P$-value from chi-squared test.

were estimated at $-0.16(-0.25 ;-0.07),-0.13(-0.23$; $-0.04),-0.01(-0.13 ; 0.11)$, and $0.08(-0.05 ; 0.21)$ for treatment cows from 0 to 30,30 to 60,60 to 90 , and after 90 DIM, respectively. The lameness score analyzed on the original scale with the random regression model showed no significant effect of treatment index.

\section{Herd Effects}

Overall, the production and management systems were considered not to differ from typical systems in current Danish dairy herds. Interaction between herd and treatment was found for only a few response variables. In general, the models controlled for the herd factor. The low number of herds meant that interactions between treatment and herd characteristics could not be assessed. Because of the number of observations, interactions between parity and treatment were analyzed only in the models assessing a continuous response.

\section{DISCUSSION}

\section{Evaluation of the Hypothesis}

In this study, cows selected for treatment were housed for 1 mo after calving in a separate section and cows se- lected as controls were housed in the remaining section of the barn. The analysis of the effect of separate housing showed that primiparous cows produced more milk, whereas multiparous and especially parity $3+$ cows produced less milk during lactation. Separate housing had no effect on mortality or on reproduction efficiency and reduced the number of medical treatments for ketosis in primiparous cows. Clinical examinations showed that separate housing decreased the scores for hock lesions 0 to 30 DIM, whereas the leg cleanliness was reduced (higher leg hygiene score). Body condition score was reduced 0 to $60 \mathrm{~d}$ after calving.

Based on these results, the hypothesis that the treatment would lead to greater production because of separate housing was confirmed in this study for primiparous cows but not for multiparous cows, which actually produced less milk. The hypothesis regarding a reduction in health problems was evaluated on various variables and confirmed in this study only with regard to fewer primiparous cows being treated for ketosis.

\section{Milk Yield}

Primiparous cows produced more milk, whereas multiparous and especially parity $3+$ cows produced less milk during the lactation. The separation of prim-

Table 6. Effects of separate housing for 1 mo after calving on odd ratios (OR) of hock lesions and leg cleanliness (dirty legs) in separate periods after calving estimated for 217 treatment cows versus 272 control cows

\begin{tabular}{|c|c|c|c|c|c|}
\hline \multirow[b]{2}{*}{ Response } & \multirow[b]{2}{*}{$P$-value ${ }^{1}$} & \multirow[b]{2}{*}{ Period (DIM) } & \multirow[b]{2}{*}{ OR } & \multicolumn{2}{|c|}{$95 \% \mathrm{CI}$} \\
\hline & & & & Lower & Upper \\
\hline \multirow[t]{4}{*}{ Hock lesions } & 0.034 & 0 to 30 & 0.41 & 0.19 & 0.91 \\
\hline & & 31 to 60 & 1.76 & 0.91 & 3.87 \\
\hline & & 61 to 90 & 1.06 & 0.51 & 2.21 \\
\hline & & After 90 & 1.36 & 0.70 & 2.73 \\
\hline \multirow[t]{4}{*}{ Leg cleanliness (dirty legs) } & 0.001 & 0 to 30 & 3.61 & 2.01 & 6.47 \\
\hline & & 31 to 60 & 1.88 & 0.97 & 3.65 \\
\hline & & 61 to 90 & 0.54 & 0.22 & 1.31 \\
\hline & & After 90 & 0.95 & 0.39 & 2.29 \\
\hline
\end{tabular}

${ }^{1} P$-value for test of treatment index defined according to occurrence of clinical score and DIM. 
iparous cows having such a positive effect on the milk yield was found only as a tendency by O'Connell et al. (2008). However, in their study, the cows were separated for only $1 \mathrm{wk}$ and this shorter period may have reduced the ability to find an effect. Whereas the primiparous cows seemed to have an advantage in separate housing, the multiparous cows seemed not to, because their milk production was decreased. A study of Phillips and Rind (2001) on primiparous and multiparous cows housed in homogeneous groups or mixed together in heterogeneous groups showed that the homogenous housing led to a $3 \%$ higher milk production in the first week for both primiparous and multiparous cows after regrouping compared with the mixed housing. A study by Brakel and Leis (1976) on production indicators after regrouping of cows showed that a loss of milk yield was connected with reduced feed intake. Furthermore, Krohn and Kongaard (1979) found that primiparous cows grouped separately spent more time eating and had a higher DMI, leading to a higher milk yield.

\section{Medical Treatments}

Separate housing reduced the number of medical treatments for ketosis in primiparous cows. Krohn and Kongaard (1979) found that separated primiparous cows not only spent more time eating and had a higher DMI, but also had a higher roughage intake. Additionally, treatment cows spent more time resting, as was found in a study on time-budget by Nielsen et al. (2008). These circumstances might have prevented the primiparous cows from developing ketosis.

\section{Reproduction}

Separate housing showed no significant effect on reproduction efficiency. O'Connell et al. (2008) did not find such an effect on primiparous cows being separated for 1 wk. Such periods of separation may be too short to improve the reproduction rate. It could be that the additional regrouping was associated with a high adaptation challenge to the new group situation (Hasegawa et al., 1997) such that it eliminated the advantage of the separation period.

\section{Clinical Scores}

The clinical evaluations showed that separate housing decreased the scores for hock lesions from 0 to 30 DIM, whereas leg cleanliness was reduced (higher scores for leg hygiene). In a study on time budgeting of early lactation cows with regard to the same treatment, Nielsen et al. (2008) found increased resting times and decreased time spent standing or walking in alleys or in collecting areas. Similarly, Proudfoot et al. (2009) found shorter standing times for cows in reduced-foodcompetition situations where there was a lower stocking density per feed bunk space. With regard to BCS, body condition was reduced 0 to $60 \mathrm{~d}$ after calving in the treatment group. O'Connell et al. (2008) found no effect on BCS in primiparous cows after a 1-wk separation postcalving.

\section{Practical Application of the Results}

In recent years, there has been much debate among Danish dairy farmers about the possible benefits of separate housing of early lactation cows. Many farmers have had their own experience with separating groups of cows. Some farmers find that at least some cows benefit from separate housing during early lactation. However, there is a need for a controlled clinical trial to evaluate the possible benefits. In such a clinical trial, it is imperative that rigorous protocols be used regarding the movement of cows between groups. In actual practice, farmers typically transfer cows from the early lactation group to a larger group of regular lactation cows based on an evaluation of the individual cow. The cow is typically moved when the farmer believes she is ready for it and not strictly based on DIM. Some cows might be judged ready for movement $14 \mathrm{~d}$ after calving and others not until $40 \mathrm{~d}$ after calving. Additionally, the number of cows calving during a certain period (and hence capacity in the separate sections of the barn) might influence movements of cows to and from the separate group.

Based on the results from the present study, the benefits for the cows are relatively small. Farmers should not invest much money in separate housing of early lactation cows and expect to gain many benefits from it. However, the cows in the separate groups were fed the same feed as the rest of the lactating cows, whereas in many practical settings, farmers might choose to feed the early lactation cows differently, and this might in turn mean additional benefits of separate housing. It is expected that farmers experience more benefits from separate housing of early lactation cows in practice compared with this experiment.

That an increase in milk yield was found only for primiparous cows was not surprising because primiparous cows generally have a low social status in a dairy herd and they were expected to benefit more from an easier access to resources such as feed and resting places (Phillips and Rind, 2001).

It might be speculated that the increasing number of movements between groups experienced by the cows in the treatment group in this experiment could have a negative effect on overall performance and thereby 
minimize the possible positive effects of separate housing during early lactation. Regrouping is known to have negative effects on milk production, feeding time, resting behavior, and social activities (von Keyserlingk et al., 2008). The possible effects of this might be studied in the future.

\section{CONCLUSIONS}

The hypothesis that separate housing for 1 mo after calving would increase the milk yield was supported by our results for primiparous cows but not for multiparous cows (who actually produced less milk). The hypothesis about fewer health problems was evaluated on various variables and could be confirmed only with regard to fewer primiparous cows being treated for ketosis.

\section{ACKNOWLEDGMENTS}

We thank the farmers participating for their hospitality and interest.

\section{REFERENCES}

Albeni, F., and G. Betoni. 2009. Main causes of poor welfare in intensively reared dairy cows. Ital. J. Anim. Sci. 8(Suppl.1):45-66.

Bach, A., C. Iglesias, M. Devant, and N. Rafols. 2006. Performance and feeding behaviour of primiparous cows loose housed alone or together with multiparous cows. J. Dairy Sci. 89:337-342.

Bennedsgaard, T. W., C. Enevoldsen, S. M. Thamsborg, and M. Vaarst. 2003. Effect of mastitis treatment and somatic cell counts on milk yield in Danish organic dairy cows. J. Dairy Sci. 86:3174-3183.

Bøe, K. E., and G. Færevik. 2003. Grouping and social preferences in calves, heifers and cows. Appl. Anim. Behav. Sci. 80:175-190.

Brakel, W. J., and R. A. Leis. 1976. Impact of social disorganization on behaviour, milk yield, and body weight of dairy cows. J. Dairy Sci. 59:716-721.

Caraviello, D. Z., K. A. Weigel, P. M. Fricke, M. C. Wiltbank, M. J. Florent, N. B. Cook, K. V. Nordlund, N. R. Zwald, and C. L. Rawson. 2006. Survey of management practices on reproductive performance of dairy cattle on large US commercial farms. J. Dairy Sci. 89:4723-4735.

Danish Agriculture and Food Council. 2009. http://www.landbrugsinfo. dk/kvaeg/filer/kvaegbruget_tal2009eng.pdf Accessed March 2010.

Ferguson, J. D., D. T. Galligan, and N. Thomsen. 1994. Principal descriptors of body condition score in Holstein cows. J. Dairy Sci. $77: 2695-2703$.
Hasegawa, N., A. Nishiwaki, K. Sugawara, and I. Ito. 1997. The effects of social exchange between two groups of lactating primiparous heifers on milk production, dominance order, behaviour and adrenocortical response. Appl. Anim. Behav. Sci. 51:15-27.

Kjæstad, H. P. 1999. Cubicle sheds for dairy cows. A field study of the use of cubicles, of the use of the concentrate feed, dispenser and of the management of calving. DVM thesis. The Norwegian School of Veterinarian Science, Oslo.

Krohn, C. C., and S. P. Kongaard. 1979. Effects of isolating first lactation cows from older cows. Livest. Prod. Sci. 6:137-146.

Molenberghs, G., and G. Verbeke. 2005. Models for Discrete Longitudinal Data. Springer Science+Business Media Inc., New York, NY.

Nielsen, T. R., E. Burow, P. T. Thomsen, and S. Østergaard. 2008. Time budgets of dairy cows housed in smaller groups during the first 30 days of lactation. Page 86 in Book of Abstracts, 4th Int. Workshop on the Assessment of Animal Welfare at Farm and Group Level, Ghent, Belgium.

O'Connell, N. E., H. C. F. Wicks, A. F. Carson, and M. A. McCoy. 2008. Influence of post-calving regrouping strategy on welfare and performance parameters in dairy heifers. Appl. Anim. Behav. Sci. 114:319-329.

Phillips, C. J. C., and M. I. Rind. 2001. The effect on production and behavior of mixing uniparous and multiparous cows. J. Dairy. Sci. 84:2424-2429.

Proudfoot, K. L., D. M. Veira, D. M. Weary, and M. A. G. von Keyserlingk. 2009. Competition at the feed bunk changes the feeding, standing and social behavior of transition cows. J. Dairy Sci. 92:3116-3123.

Rioja-Lang, F. C., D. J. Roberts, S. D. Healy, A. B. Laurance, and M. J. Haskell. 2009. Dairy cows trade-off feed quality with proximity to a dominant individual in Y-maze choice tests. Appl. Anim. Behav. Sci. 117:159-164.

SAS Institute. 2009. SAS Online Doc 9.2. SAS Institute Inc., Cary, NC.

Schreiner, D. A., and P. L. Ruegg. 2003. Relationship between udder and leg hygiene scores and subclinical mastitis. J. Dairy Sci. 86:3460-3465.

Strandberg, E., and C. Lundberg. 1991. A note on the estimation of environmental effects on lactation curves. Anim. Prod. 53:399 402.

Thomsen, P. T., and N. P. Baadsgaard. 2006. Intra- and inter-observer agreement of a protocol for clinical examination of dairy cows. Prev. Vet. Med. 75:133-139.

Thomsen, P. T., S. Østergaard, J. T. Sørensen, and H. Houe. 2007. Loser cows in Danish dairy herds: Definition, prevalence and consequences. Prev. Vet. Med. 79:116-135.

von Keyserlingk, M. A. G., D. Olenick, and D. M. Weary. 2008. Acute behavioral effects of regrouping dairy cows. J. Dairy Sci. 91:10111016 . 